\title{
Efektifitas Media Pembelajaran Melalui Model Discovery Learning terhadap Minat dan Hasil Belajar Peserta Didik SDN 193 Pekanbaru
}

\author{
Hayatun Najmi*, Yayuk Cicilia**, Rian Vebrianto*** \\ ${ }^{*, * *}$ Magister PGMI, Universitas Islam Negeri Sultan Syarif Kasim Riau \\ ${ }^{* * *}$ Universitas Islam Negeri Sultan Syarif Kasim Riau
}

\section{INFO ARTIKEL}

Riwayat Artikel:

Diterima: 02-04-2020

Disetujui: 18-04-2020

Kata kunci:
Efektifitas
Media Pembelajaran
Model Discovery Learning
Minat dan Hasil Belajar

Alamat Korespondensi:

Hayatun Najmi,

Magister PGMI, Universitas Islam Negeri Sultan Syarif Kasim Riau

Jl.HR. Soebrantas Panam Km.15 No. 155 Kec. Tampan

E-mail: hayatun.m4@gmail.com

\begin{abstract}
This study aims to determine the effect of the use of science learning media on discovery learning models on the interests and achievements of student learning outcomes in alternative energy materials. This study uses an experimental method, the sample consists of 2 classes, cognitive learning achievement data using tests, affective aspects of learning achievement using a questionnaire, hypothesis testing using the right-hand t-test. The data analysis technique used is the n-gain test and independent sample t-test using SPSS version 16.0. The results showed that students who were taught using science learning media on discovery learning models gave a good influence on students' interest and learning achievement better than students who were taught the lecture method. Students with high learning interest produce better average achievement than students with low learning interest, and there is an increase in student learning achievement using learning media.
\end{abstract}

\begin{abstract}
Abstrak: Penelitian ini bertujuan untuk mengetahui pengaruh penggunaan media pembelajaran IPA pada model discovery learning terhadap minat dan prestasi hasil belajar siswa pada materi energi alternatif. Penelitian ini menggunakan metode eksperimen, sampel terdiri dari 2 kelas, data prestasi belajar kognitif menggunakan tes, prestasi belajar aspek afektif menggunakan angket, uji hipotesis menggunakan uji t-pihak kanan. Teknik analisis data yang digunakan, yaitu uji ngain dan uji independent sample t-test menggunakan SPSS versi 16.0. Hasil penelitian menunjukkan bahwa siswa yang diajar menggunakan media pembelajaran IPA pada model pembelajaran discovery learning memberikan pengaruh yang baik terhadap minat dan prestasi belajar siswa lebih baik dibandingkan dengan siswa yang diajar metode ceramah. Siswa dengan minat belajar yang tinggi menghasilkan rata-rata prestasi lebih baik daripada siswa dengan minat belajar yang rendah, serta terdapat peningkatan pada prestasi belajar siswa belajar dengan menggunakan media pembelajaran.
\end{abstract}

\section{LATAR BELAKANG}

Proses pengajaran yang baik harus mengacu pada kurikulum yang berlaku. Kurikulum adalah rangkaian rencana isi yang akan menjadi sejumlah tahapan belajar yang didesain untuk siswa dengan petunjuk institusi pendidikan yang isinya berupa proses. IPA merupakan salah satu mata pelajaran yang sangat penting dan selalu diberikan pada setiap jenjang pendidikan tersebut. Tetapi, pembelajaran IPA di SD, hingga dewasa ini sering melupakan dimensi proses yang ada. Agar siswa mudah memahami materi yang diajarkan, maka guru perlu menggunakan pendekatan, strategi metode, dan teknik pembelajaran, namun masih sering terdengar keluhan dari para guru di lapangan untuk menentukan model pembelajaran yang sesuai dengan karakter materi pembelajaran. Dalam hal ini guru hanya 
sebagai pembimbing dan fasilitator siswa agar mampu mengembangkan potensinya secara optimal. Salah satu model pembelajaran yang mampu mengembangkan peran guru sebagai pembimbing dan fasilitator untuk mengembangkan potensi siswa yaitu model pembelajaran disscovery learning. Joolingen (dalam Rohim, dkk., 2012) menjelaskan bahwa discovery learning adalah suatu tipe pembelajaran dimana siswa membangun pengetahuan mereka sendiri dengan mengadakan suatu percobaan dan menemukan sebuah prinsip dari hasil percobaan tersebut. Discovery learning merupakan komponen dari praktek pendidikan yang meliputi metode mengajar yang memajukan cara belajar aktif, berorientasi pada proses, mengarahkan sendiri dan reflektif (Suryosubroto, 2002). Penerapan model pembelajaran discovery learning di SD terutama pada mata pelajaran IPA menjadi sangat tepat dikarenakan model pembelajaran ini memiliki beberapa kelebihan. Model pembelajaran discovery learning memiliki beberapa kelebihan, yaitu: 1) menambah pengalaman siswa dalam belajar, 2) memberikan kesempatan kepada siswa untuk lebih dekat lagi dengan sumber pengetahuan selain buku, 3) menggali kreatifitas siswa, 4) mampu meningkatkan rasa percaya diri pada siswa, dan 5) meningkatkan kerja sama antar siswa. Hal tersebut lebih didukung lagi berdasarkan beberapa hasil penelitian yang pernah dilakukan dengan menerapkan model pembelajaran discovery learning.

Oleh karena itu seorang guru perlu memiliki kemampuan merancang dan mengimplementasikan berbagai model pembelajaran yang dianggap cocok dengan minat dan bakat serta sesuai dengan taraf perkembangan atau karakteristik siswanya. Ada tiga model pembelajaran yang diterapkan pada kurikulum 2013 yaitu model pembelajaran discovery learning, model pembelajaran berbasis masalah dan model pembelajaran berbasis proyek (Kurniasih dan Sani, 2014). Model discovery learning merupakan komponen dari suatu bagian praktek pengajaran, yaitu suatu jenis mengajar yang meliputi metodemetode yang dirancang untuk meningkatkan rentangan keaktifan siswa yang lebih besar, berorientasi kepada proses, mengarahkan pada diri sendiri, mencari sendiri dan refleksi yang sering muncul sebagai kegiatan belajar. Discovery adalah proses mental dimana siswa mampu mengasimilasikan sesuatu konsep atau prinsip. Proses mental yang dimaksud adalah mengamati, mencerna, mengerti, menggolonggolongkan, membuat dugaan, menjelaskan, mengukur, membuat kesimpulan dan sebagainya (Roestiyah, 2001). Oleh sebab itu, dengan model discovery learning, siswa akan mampu menyimpan pengetahuan lebih lama dalam memorinya karena mereka menemukan sendiri jawabannya. Pengetahuan yang tersimpan dalam memori diharapkan mampu menimbulkan nilai-nilai perilaku yang baik bagi anak dan dari perilaku yang baik itu, menjadi sebuah kebiasaan bagi anak dan menimbulkan keterampilan yang berguna bagi masyarakat lainnya. Ilmu Pengetahuan Alam (IPA) berhubungan dengan cara mencari tahu tentang alam secara sistematis, sehingga IPA bukan anya penguasaan kumpulan pengetahuan yang berupa fakta-fakta, konsep-konsep, atau prinsipprinsip saja tetapi juga merupakan suatu proses penemuan (Wisudawati \& Sulistyowati, 2014).

Pembelajaran IPA sebaiknya dilaksanakan secara discovery learning untuk menumbuhkan kemampuan berpikir, bekerja dan bersikap ilmiah serta mengkomunikasikannya sebagai aspek penting kecakapan hidup.Pembelajaran dilakukan lebih mengutamakan dimensi produk yang berupa hasil pada buku saja. Dimensi proses sangat penting dalam menunjang perkembangan siswa memperoleh pengetahuan tetapi juga memperoleh kemampuan untuk menggali dan menemukan pengetahuan itu sendiri. Dalam perkembangannya sampai saat ini, tampak jelas bahwa masalah yang serius dalam peningkatan kualitas pendidikan di Indonesia adalah rendahnya kualitas pendidikan di berbagai jenjang pendidikan, baik pendidikan formal maupun informal. Gunawan (2013) menyatakan pendidikan Indonesia berada di peringkat ke-64 untuk pendidikan di seluruh dunia dari 120 negara. Rendahnya kualitas pendidikan pada jenjang formal maupun informal terjadi pada lima mata pelajaran yang diutamakan khususnya pada jenjang SD. Rendahnya kualitas pendidikan pada kelima mata pelajaran tersebut harus segera dicarikan jalan keluarnya. Terutama rendahnya kualitas pendidikan pada mata pelajaran IPA. Berkaitan dengan proses pembelajaran IPA, berdasarkan hasil wawancara dan pencatatan dokumen di kelas IV SDN 193 Pekanbaru mengenai hasil belajar IPA masih belum optimal. Dari observasi yang dilakukan terungkap beberapa permasalahan yang teridentifikasi menyebabkan rendahnya hasil belajar IPA siswa kelas IV SDN 193 Pekanbaru. Salah satu masalah yang dihadapi 
adalah masalah lemahnya pelaksanaan proses pembelajaran IPA yang diterapkan guru. Dapat dikatakan bahwa pembelajaran IPA yang dilakukan oleh guru masih dilakukan secara konvensional.

Para guru belum sepenuhnya melaksanakan pembelajaran secara aktif dan kreatif dalam melibatkan siswa. Pembelajaran IPA masih didominasi metode ceramah dan pemberian tugas. Selain itu, dalam proses pembelajaran kebanyakan guru hanya terpaku pada buku teks sebagai satu-satunya sumber belajar mengajar. Kebanyakan guru tidak melakukan kegiatan pembelajaran yang memperhatikan dimensi dari IPA dan tinggi rendahnya minat belajar yang dimiliki oleh siswa. Dimensi dari IPA yang dimaksud yaitu IPA sebagai produk dan proses. Berdasarkan permasalahan yang dipaparkan, maka dilakukan penelitian ini dengan tujuan untuk mengetahui efektivitas media pembelajaran serta hasil belajar IPA antara kelompok siswa yang mengikuti pembelajaran dengan menggunakan model discovery learning dengan model konvensional, dengan melibatkan minat belajar pada siswa kelas IV sekolah dasar negeri 193 Pekanbaru, tahun ajaran 2019/2020.

\section{METODE}

Penelitian ini termasuk jenis penelitian eksperimen semu (quasi experiment) karena tidak semua variabel (gejala yang muncul) dan kondisi eksperimen dapat diatur dan dikontrol secara ketat. Sedangkan rancangan penelitian yang digunakan dalam penelitian ini yaitu post-test only control group design.

Tabel 1. Desain Penelitian Tipe Two GroupPretest-Postest

\begin{tabular}{lccc}
\hline \multicolumn{1}{c}{ Kelas } & Pretes & Perlakuan & Postes \\
\hline Eksperimen & $\mathrm{Y} 1$ & $\mathrm{X} 1$ & $\mathrm{Y} 2$ \\
Kontrol & $\mathrm{Y} 1$ & $\mathrm{X} 2$ & $\mathrm{Y} 2$ \\
\hline
\end{tabular}

Keterangan:

$\mathrm{X} 1=$ Pembelajaran dengan menggunakan model pembelajaran discovery Learning.

$\mathrm{X} 2=$ Pembelajaran denganmenggunakan pembelajaran konvensional

Y1 = Pretes diberikan pada kelas eksperimen dan kelas kontrol sebelum perlakuan.

Y2 = Postes diberikan setelah perlakuan pada kelas eksperimen dan kelas kontrol.

Tempat pelaksanaan penelitian ini adalah Sekolah Dasar Negeri 193 Pekanbaru pada tahun ajaran 2019/2020. Populasi dalam penelitian ini yaitu seluruh siswa kelas IV SDN 193 Pekanbaru yang berjumlah 64 siswa. Sampel dalam penelitian ini yaitu 32 orang siswa kelas IV A sebagai kelas eksperimen yang menggunakan model discovery learning dan siswa kelas IV B yang berjumlah 32 orang sebagai kelas kontrol yang menggunakan pembelajaran konvensional. Hasil belajar dan minat belajar siswa menggunakan media pembelajaran dengan model discovery learning dikumpulkan melalui kuisioner dan tes hasil belajar kemudian dianalisis menggunakan bantuan program SPSS.

\section{HASIL DAN PEMBAHASAN}

Dari kuisioner yang dibagikan kepada 64 responden dikalangan siswa IV SDN 193 Pekanbaru mengenai beberapa hal diantaranya penggunaan media belajar energi alternatif, metode mengajar guru, motivasi dan efektifitas penggunaan media belajar. Dari hasil kuisioner mengenai penggunaan media belajar mengenai membuat tabung oksigen sederhana didapatkan hasil sebagai berikut. 
Tabel 2. Nilai Rata-Rata Kuisioner Media Pembelajaran yang Digunakan

\begin{tabular}{clcc}
\hline No & \multicolumn{1}{c}{ Pertanyaan } & $\begin{array}{c}\text { Nilai Rata-rata Hasil } \\
\text { Kuisioner }\end{array}$ & Keterangan \\
\hline 1. $\begin{array}{l}\text { Saya lebih mudah memahami pelajaran tentang media energi } \\
\text { alternatif dalam kehidupan sehari-hari dalam mengatasi } \\
\text { semakin menipisnya energi yang tidak dapat di perbarui } \\
\text { setelah guru menggunakan media pembelajaran }\end{array}$ & 2,85 & Iya \\
2. Saya merasa bosan jika kegiatan belajar mengajar tidak \\
$\begin{array}{l}\text { menggunakan media pembelajaran } \\
\text { 3. } \begin{array}{l}\text { Media tentang energi alternatif dalam kehidupan sehari-hari } \\
\text { dalam mengatasi semakin menipisnya energi yang tidak }\end{array}\end{array}$ & Tidak \\
$\begin{array}{l}\text { dapat di perbarui mudah dipraktekkan } \\
\text { Media yang digunakan kurang menarik }\end{array}$ & Iya \\
5. $\begin{array}{l}\text { Dengan menggunakan media pelajaran saya dapat membuat } \\
\text { media yang sedernaha menggunakan apel dan jeruk sebagai } \\
\text { energi alternatif untuk menyalakan sebuah lampu tanpa } \\
\text { menggunakan energi listrik }\end{array}$ & Tidak \\
\hline
\end{tabular}

Hasil quisioner mengenai tanggapan 64 responden siswa kelas IV SDN 193 Pekanbaru terhadap metode mengajar guru ditampilkan dalam Tabel 3 berikut.

Tabel 3. Hasil Rata-rata Kuisioner Metode Mengajar Guru

\begin{tabular}{llcc}
\hline No & \multicolumn{1}{c}{ Pertanyaan } & $\begin{array}{c}\text { Nilai Rata-rata } \\
\text { Hasil Kuisioner }\end{array}$ & Keterangan \\
\hline 1. & Guru menguasai materi pelajaran yang disampaikan & 2,98 & Iya \\
2. & $\begin{array}{l}\text { Guru menyampaikan materi pelajaran disertai dengan } \\
\text { contoh-contoh }\end{array}$ & 3,56 & Iya \\
3. $\begin{array}{l}\text { Dalam menerangkan, guru menggunakan bahasa yang } \\
\text { mudah dipahami oleh siswa }\end{array}$ & 3,55 & Iya \\
4. $\begin{array}{l}\text { Guru menyampaikan materi pelajaran dengan suara yang } \\
\text { jelas }\end{array}$ & 3,43 & Iya \\
5. Setiap ada pertanyaan dari siswa, guru akan menjelaskan \\
sampai siswa itu jelas
\end{tabular}

Penggunaan media pembelajaran diharapkan mampu meningkatkan efektifitas belajar mengajar. Hasil rata-rata quisioner efektifitas penggunaan media belajar pembuatan tabung oksigen sederhana dapat dlihat pada Tabel 4 berikut.

Tabel 4. Hasil Rata-rata Kuisioner Motivasi Peserta Didik Efektifitas Media

\section{No Pertanyaan}

1. Saya tidak merasakan manfaat media pembelajaran

2. Dengan menggunakan media pembelajaran, pembelajaran menjadi lebih efektif dan efisien

3. Media pembelajaran membuat saya lebih fokus belajar dalam membuat rancangan percobaan

4. Media pembelajaran membuat saya lebih bertanggung jawab atas apa yang ditugaskan guru

5. Saya lebih suka membaca teks daripada menggunakan media pembelajaran
Nilai Rata-Rata Hasil Kuisioner

\section{Keterangan}

\begin{tabular}{ll}
2,11 & Tidak \\
3,91 & Iya \\
3,98 & Iya \\
3,90 & Iya \\
2,12 & Tidak \\
\hline
\end{tabular}


Data yang diperoleh dalam penelitian ini dikelompokkan menjadi (1) hasil belajar IPA siswa yang mengikuti model pembelajaran discovery learning, (2) hasil belajar IPA siswa yang mengikuti model pembelajaran konvensional. Pembahasan dalam artikel bertujuan untuk: (1) mengikuti pembelajaran dengan model pembelajaran konvensional, (3) hasil belajar IPA siswa yang mengikuti model pembelajarn discovery learning pada kelompok siswa yang mempunyai minat belajar tinggi, (4) hasil belajar IPA siswa yang mengikuti model pembelajarn discovery learning pada kelompok siswa yang mempunyai minat belajar rendah, (5) hasil belajar IPA siswa yang mengikuti model pembelajarn konvensional pada kelompok siswa yang mempunyai minat belajar tinggi, (6) hasil belajar IPA siswa yang mengikuti model pembelajarn konvensional pada kelompok siswa yang mempunyai minat belajar rendah.

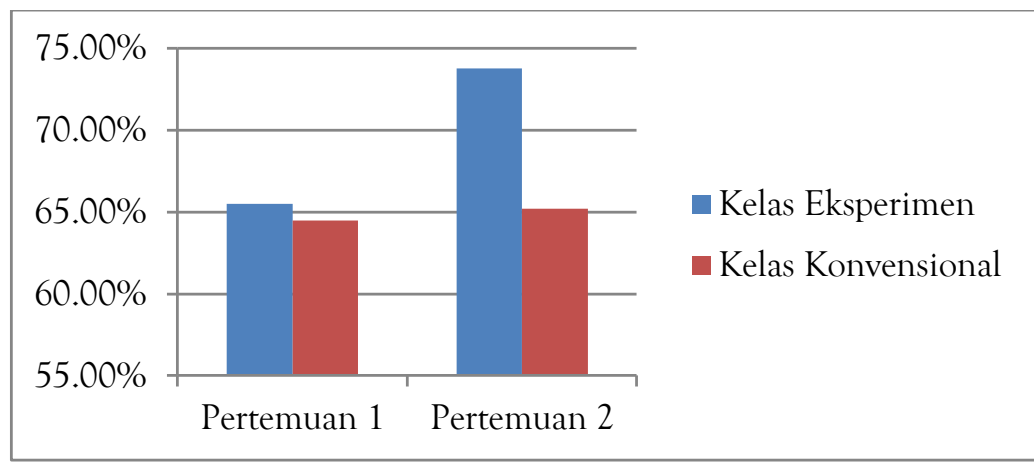

Gambar 1. Hasil Belajar Siswa

Berdasarkan Gambar 1 di atas, diperoleh informasi bahwa data pretes kedua kelas normal, homogen dan tidak ada perbedaan secara signifikan, maka pada kedua kelas sampel diberikan perlakuan yang berbeda, pada kelas eksperimen diberikan perlakuan dengan menerapkan model pembelajaran Discovery Learning sedangkan pada kelas kontrol diberikan perlakuan dengan menerapkan pembelajaran konvensional. Setelah diberikan perlakuan yang berbeda, kedua kelas diberikan postes untuk melihat adanya perbedaan akibat penerapan model pembelajaran yang berbeda. Kelas eksperimen menunjukkan bahwa terjadi peningkatan hasil belajar.Dalam suatu artikel, kadang-kadang tidak bisa dihindari pengorganisasian penulisan hasil penelitian ke dalam "anak subjudul". Berikut ini adalah cara menuliskan format pengorganisasian tersebut, yang di dalamnya menunjukkan cara penulisan hal-hal khusus yang tidak dapat dipisahkan dari sebuah artikel.

\section{SIMPULAN DAN SARAN Simpulan}

Setelah melakukan penelitian, perhitungan data, dan pengujian hipotesis, maka diperoleh beberapa kesimpulan bahwa, hasil belajar siswa pada materi pokok suhu dan kalor yang diberi pembelajaran model pembelajaran Discovery Learning lebih baik dari pada model pembelajaran konvensional. Dari hasil penelitian ini dapat disimpulkan bahwa: 1) media pembelajaran merupakan alat atau perangkat untuk menyampaikan pesan-pesan materi kepada siswa; 2) media belajar mampu membuat siswa menjadi lebih memahami dalam penggunaan energi alternatif pada kehidupan seharihari; 3) media belajar dapat meningkatkan motivasi belajar siswa; dan 4) media belajar terbukti efektif untuk digunakan dalam proses belajar mengajar.

\section{Saran}

Dari penelitian ini, penulis menyarankan dalam kegiatan pembelajaran agar dapat menggunakan media pembelajaran untuk memicu semangat dan konsentrasi peserta didik serta penulis menyarankan untuk melakukan pengembangan media belajar yang lebih inovatif dan kreatif. 
48 Instructional Development Journal (IDJ), Vol. 3, No. 1, April 2020, Hal. 43-48

\section{DAFTAR RUJUKAN}

Asih Widi Wisudawati, Eka Sulistyowati. (2014). Metodologi Pembelajaran IPA. Jakarta: Bumi Aksara.

Berlin Sani. (2014). Strategi Pembelajaran di Dalam Kelas. Bandung: Alfabeta.

Campbell, Neil A., Reece, J.B., Urry, L.A., Cain, M.L., Wasserman, S.A., Minorsky, P.V., dan Jackson, R.B. (2012). Biologi (Edisi Kedelapan Jilid 2). Jakarta: Erlangga.

Diana Hernawati. (2015). Penuntun Praktikum Botani Cryptogamae. Tasikmalaya: Universitas Siliwangi.

Edi Hernawan. (2016). Pengantar Statistika Parametrik Untuk Penelitian Pendidikan. Tasikmalaya: LPPM UNSIL.

Fathur Rohim, dkk. (2012). Penerapan Model Discovery Terbimbing Pada Pembelajaran Fisika untuk Meningkatkan Kemampuan Berpikir Kreatif. Unnes Physics Education Journal, 1(1).

Iman Gunawan. (2013). Metode Penelitiaan Kualitatif :Teori dan Pratilik. Jakarta: Bumi Aksara

M.Hosnan. (2014). Pendekatan Saintifik dan Kontekstual dalam Pembelajaran Abad 21. Bogor: Ghalia Indonesia.

Muhammad Fathrrohman. (2015). Model-Model Pembelajaran Inovatif Alterantif Desain Pembelajaran yang Menyenangkan. Yogyakarta: Ar-Ruzz Media.

Roestiyah NK. (2001). Strategi Belajar Mengajar. Jakarta: Rineka Cipta.

Suharsimi Arikunto. (2013). Prosedur Penelitian: Suatu Pendekatan Praktik. Jakarta: Rineka Cipta.

Suryosubroto. (2002). Proses Belajar Mengajar di Sekolah. Jakarta: Rineka Cipta.

Zainal Aqib. (2013). Model-Model, Media, dan Strategi Pembelajran Kontekstual (Inovatif). Bandung: Yrama Widya. 